\title{
Logical space and phase-space
}

Book or Report Section

Accepted Version

Preston, J. (2015) Logical space and phase-space. In: Mind, language and action: proceedings of the 36th International Wittgenstein Symposium. Publications of the Austrian Ludwig Wittgenstein society - New Series (N.S.) (22). De Gruyter, pp. 35-44. ISBN 9783110378795 Available at http://centaur.reading.ac.uk/38505/

It is advisable to refer to the publisher's version if you intend to cite from the work. See Guidance on citing.

Published version at: http://www.degruyter.com/view/product/433938

Publisher: De Gruyter

All outputs in CentAUR are protected by Intellectual Property Rights law, including copyright law. Copyright and IPR is retained by the creators or other copyright holders. Terms and conditions for use of this material are defined in the End User Agreement. 


\section{CentAUR}

Central Archive at the University of Reading

Reading's research outputs online 


\title{
Logical Space and Phase-Space
}

\begin{abstract}
One prominent account of Wittgenstein's notion of logical space, due to Stephen Toulmin and Allan Janik, ties that notion to the notion of phase-space in the scientific work of Ludwig Boltzmann. I cast doubt upon this attempt to link these notions, and evaluate whether any of the classic conceptions of logical space in the early commentaries on the Tractatus make logical space into a kind of phase-space. I conclude that for Wittgenstein and these commentators, logical space is a quasi-linguistic space, but that this is what precludes it being at the same time a phase-space.
\end{abstract}




\section{Introduction}

Given its importance in the Tractatus, and its influence beyond that book, the existing scholarly literature features remarkably few accounts of Wittgenstein's notion of logical space. One prominent such account, originally suggested by Stephen Toulmin and then elaborated upon in Allan Janik \& Toulmin's book Wittgenstein's Vienna, ties that notion to the notion of phasespace in the scientific work of Ludwig Boltzmann and Heinrich Hertz. I will cast doubt upon this attempt to link these notions, and evaluate whether any of the classic conceptions of logical space in the early commentaries on the Tractatus make logical space into a kind of phase-space. I conclude that for Wittgenstein and these commentators, logical space is a quasi-linguistic space, but that this very fact is what precludes it being at the same time a phase-space, properly so-called.

\section{Logical Space and Phase-Space}

One aspect of Ludwig Boltzmann's scientific work that has sometimes been thought to leave its mark on the Tractatus is his development of the idea of phase space. Stephen Toulmin seems to have been the first person to make this suggestion, in a 1969 article on Wittgenstein where he claimed that: 'the pages of the Tractatus echo with phrases - "logical spaces", comprising "ensembles of possibilities" etc. - which have roots in Boltzmann's generalised thermodynamics' (Toulmin 1969a, p.66). In another article from the same year we find Toulmin claiming: 'An axiomatic theory, [Wittgenstein] had argued, defines only a formal ensemble of possibilities in "logical space". (It was no accident that he had borrowed his nomenclature from Boltzmann's and Liouville's statistical thermodynamics)' (Toulmin 1969b, p.38).

A few years later, in Wittgenstein's Vienna, Toulmin and Allan Janik explained Boltzmann's procedure thus: 
Boltzmann took Hertz's account of mechanics as defining a system of 'possible sequences of observed events' and made it the starting point for a general method of theoretical analysis in physics itself. He did so, by treating each independent property of a physical system as defining a separate coordinate in a multidimensional system of geometrical coordinates. All the possible locations of each separate body in the physical system, for instance, were ordered along three spatial 'axes of reference'; all values of, say, temperature, along another axis; all values of, say, pressure, along a fifth; and so on. The totality of theoretical 'points' in the resulting multidimensional coordinate system gave one a representation of the 'ensemble of possible states' of the physical system in question; and any actual state could be defined by specifying the particular point in this 'multidimensional space' whose coordinates corresponded to the actual values of all the variables. The general problem for statistical mechanics was then to discover mathematical relations governing the frequencies with which - on various assumptions and conditions - the actual states of a physical system would be distributed among its possible states; and, so, to compute the relative probabilities of finding the system, in actual fact, in one overall physical state rather than another (Janik \& Toulmin 1973, pp.143-4).

Janik and Toulmin then make the link to the Tractatus thus:

this notion of a 'space of theoretical possibilities', which plays the key part in Boltzmann's method of analysis, can be summarised concisely in words from Wittgenstein's Tractatus Logico-Philosophicus as follows: The facts in logical space are the world [1.13]; the world divides into facts [1.2]; each item can be the case or not the case while everything else remains the same... [1.21] We construct for ourselves representations 
[Bilder] of facts [2.1]. A Bild depicts reality by representing a possibility of existence and non-existence of states of affairs [2.201]. A Bild represents a possible situation in logical space [2.202]. A proposition determines a place in logical space... [3.4] In geometry and logic alike a place is a possibility: something can exist in it [3.411]. (ibid., p.144). ${ }^{1}$

Among more recent commentators, Michael Lockwood certainly endorses Janik and Toulmin's claim that Wittgenstein's concept of logical space is 'transparently modelled on Boltzmann's use of the concept of phase space', adding that Boltzmann thus 'unwittingly made his mark on philosophy as well as physics' (Lockwood 2005, p.219).

\section{Evaluation of these Claims}

These claims have several problematic features. First, the idea that Boltzmann made Hertz's account of mechanics the starting point for a general method of theoretical analysis in physics is demonstrably false. Hertz's Principles of Mechanics (1894) had been published by the time Boltzmann published the work in question here, his Vorlesungen über Gastheorie (1896, 1898). But Boltzmann mentions Hertz's book only once in these lectures, and there specifically to remark that he had 'abandoned' his own attempt to try out 'a gas theory in which, instead of forces acting during collisions, one merely has conditional equations in the sense of the posthumous mechanics of Hertz' (Boltzmann 1964, p.26). In fact, Boltzmann was never very impressed by Hertz's mechanics, finding it unworkable even on simple problems, and he did not model any of his own work on it. The fairly common assumption, by Wittgenstein scholars, that Boltzmann somehow developed Hertz's mechanics,

\footnotetext{
1 These ideas don't feature in the chapter on Boltzmann in Janik's much later book Assembling Reminders (Janik 2006), but Janik is there concerned with influences on Wittgenstein's later philosophy.
} 
is a complete myth.

Second, Janik and Toulmin's description of phase-space is strange in that it omits what seems to be a most important aspect of that concept as it occurs in physics, which is the evolution of the system in question. That is, what physicists usually do when they represent a system in phase-space is to study the system's trajectories through that space, the way it evolves over time. Janik and Toulmin's description, by contrast, seems static, and one wonders whether they thought that Wittgenstein's notion of logical space had this same feature.

Third, and finally, claims that terms from the Tractatus ('logical space', 'ensembles of possibilities') originate either in Boltzmann's thermodynamics or in the earlier, purely mathematical work of Joseph Liouville are also clearly false. The term 'ensemble' doesn't even occur in the Tractatus, so what Toulmin meant by saying that it has roots in, and was borrowed from, Boltzmann's thermodynamics is obscure. In the aforementioned Vorlesungen über Gastheorie, (which we don't even know whether Wittgenstein had read), neither 'Ensemble' nor 'Ansammlung' occur at all, and 'Möglichkeit' (possibility) occurs only three times, none of which occurrences is suggestive of the way in which the concept is used in the Tractatus. When it comes to the concept of logical space, too, 'logisch' occurs only twice in Boltzmann's text, once in the phrase 'logisch Consequenzen', and once in 'logische Notwendigkeit' (both in §14). Related tractarian terms are also much harder to find in this same text than Janik and Toulmin's remarks lead one to expect. 'Raum' itself occurs only ten times, none of them references to anything other than ordinary physical space. Finally, the case is even shakier if we turn to Boltzmann's Vorlesungen über die Principe der Mechanik, the two volumes of which (published 1897, 1904) we do know Wittgenstein owned, since none of the terms in question occur there at all.

As for Liouville, the acclaimed author of the definitive volume on his work describes as 'absurd' the idea that he ever contributed to statistical 
mechanics, and goes on: 'It is indeed unlikely that he ever heard of this new approach to the theory of heat, which was being conceived by Maxwell, Gibbs, and Boltzmann toward the end of Liouville's life' (Lützen 1990, p.663).

If Boltzmann didn't use the expression 'logical space', did he at least have the idea? Maybe, after all, that's all that Toulmin really meant. This question factors into two: How is the idea of logical space related to the physicist's idea of phase space? And did Boltzmann have the idea of phasespace?

\section{Boltzmann's Phase-Space?}

Surprisingly, it seems that (pace Lockwood, at least) the answer to this second question is 'not quite'. As David D. Nolte explains in a recent article on the history of the idea of phase-space in Physics Today (Nolte 2010), the sequence of ideas on the topic is as follows. In 1838, Liouville (1808-1892) proved the theorem that now bears his name. In lectures given in 1842-3, Carl Gustav Jacob Jacobi (1804-1851) realised that the differential equations involved in Liouville's theorem could be applied to mechanical systems. Neither of them had the idea of representing such systems within a generalised space, though - the idea of space was still limited to physical space of three dimensions. The idea of a multidimensional space developed only gradually, and largely in the work of German and British geometers. In 1871, Boltzmann used Jacobi's results to derive a conservation theorem. His papers from that time, though, "contain no use of the language of "phase" or "space", although the conservation of what would later be called phase-space volume for a conservative dynamical system appears in its mathematically modern form' (Nolte 2010, p.35). Boltzmann used the term 'phase' for the first time in 1872, in an article in which he distinguished between the kind of atomic motion and its phase. He didn't use the term again until the publication of the first volume of his Vorlesungen über Gastheorie in 1896. Even then, though, as Nolte 
explains:

Boltzmann still does not seem able to take that final step of speaking of a single trajectory through a multidimensional space. All the mathematics is in place, and he makes the analogies and uses the geometric language of $n$-fold regions, but he implies the trajectory rather than stating it explicitly. That inability is clearly related to the fact that he never uses the word 'space', and thus does not take the last step to call it 'phase space' (Nolte ibid., p.36).

To say that Boltzmann had the idea of phase-space, then, is something of an idealisation. In fact, the first published occurrence of the term itself came as late as 1911, in a famous encyclopaedia review of Boltzmann's work, although it caught on quickly and by 1913 had been used in articles in the Annalen der Physik (Nolte ibid., p.38).

Of course physicists did have that idea by the time Wittgenstein was composing his Tractatus, since Josiah Willard Gibbs (who actually did introduce the term 'ensemble' (Nolte, p.37)) and Henri Poincaré had both made ample use of the idea (if not the term 'phase space') in their physical researches. Wittgenstein could have picked up the idea of phase space (although he could not have been aware of the term) during his training as an engineer, either in Berlin (1906-8) or in Manchester (1908-11). Claims that he got the idea from Boltzmann, though, should be treated with scepticism.

\section{Is Logical Space Phase-Space?}

At this point we come to the important question. Boltzmann aside, is the 'logical space' of the Tractatus a kind of phase-space?

Given that 'logical space' is one of the most famous Tractarian concepts, and given the importance its role can be assumed to have there, I think one has 
to say that there has been remarkably little discussion, in the scholarly literature, of exactly how (or whether) the idea might work. There are certain classic discussions in the early commentaries by Erik Stenius, James Griffin, and Max Black. Recent commentators, by contrast, hardly seem to go into the idea at all, and often never even mention it. ${ }^{2}$ Perhaps this is because they are all convinced that the idea isn't important, or that it's nothing more than a suggestive analogy. It would surely be worth seeing whether one can squeeze more out of it than that, but this is a much larger project that will not be attempted here. Instead, I will consider only whether logical space as the early commentators conceive it could be a phase-space.

\section{Anscombe on Logical Space?}

Before I come to those treatments of logical space which really concern me, though, I note that Elizabeth Anscombe has been taken to task for offering an inadequate conception of the notion in her 1959 book An Introduction to Wittgenstein's Tractatus (see Pinkerton \& Waldie 1974, pp.15-19). It's true that Anscombe, transiting very quickly and rather superficially from the notion of logical form to that of logical space, proceeds to construct what she calls 'a spatial illustration a bit like Wittgenstein's black spot on white paper' (Anscombe 1959, p.75). I've little doubt that Pinkerton and Waldie are right to complain that what follows could not be an adequate illustration of Wittgenstein's notion of logical space. But it's simply not clear that Anscombe meant it to be. Neither of Wittgenstein's mentions of black spots, to which she refers when introducing her analogy, occur within (or nearby) any of his remarks about logical space. The first occurs in Tractatus 4.063, when he gives what he calls 'an analogy to illustrate the concept of truth'. The second occurs in 6.341, when he tries to explain the nature of mechanics (although here the

\footnotetext{
${ }^{2}$ The most notable exception is David Hyder, whose book (Hyder 2002) goes into the issue in detail.
} 
black spots are on a 'white surface', and Anscombe's 'paper' isn't mentioned). I suspect Anscombe had the former illustration in mind, but Wittgenstein ties neither of them to the idea of logical space.

So I suspect either that Anscombe is not a legitimate target in this respect, and that in fact she said nothing, in that book, about logical space, or that her own association of Wittgenstein's black spots on white paper with the notion of logical space is tenuous.

\section{Logical Space in the Early Commentaries on the Tractatus}

The crucial question, when considering whether logical space, as conceived of within any given treatment, is a phase-space, is what are its denizens? That is, what kinds of things feature in logical space, as presented in that treatment? As far as I can see, the classic treatments of logical space preclude its being a phase-space, since they feature the wrong kind(s) of denizens.

The best and most detailed of these classic treatments of logical space occurs in Erik Stenius's book Wittgenstein's Tractatus: A Critical Exposition of the Main Lines of Thought, which devotes an entire chapter to the notion. Stenius begins by setting out what he calls a 'model' or 'description' of a 'world' which consists of five rectangular parallelepipeds of different shapes and sizes (Stenius 1960, pp.38-9). The description in question describes fifteen independent facts or states of affairs, the length, width and height of each of the five parallelepipeds. He then uses this notion of independence to ground the idea of the 'world' in question having different dimensions: 'a world has as many dimensions as it has mutually independent components of description' (ibid., p.40). At this point Stenius also notes the use of configuration- and phase-spaces by physicists:

[A]bove all the number of mutually independent components of 
description has been an important factor in physical world description. Our world is considered by the physicists as a world with an immense number of 'dimensions' in this sense, and therefore our model can in this respect serve as model of descriptions in physics. (ibid., p.41. In his footnote here, Stenius mentions Hertz's Principles of Mechanics as containing such a view of the world).

At this point, though, Stenius quite rightly makes it clear that the 'dimensions' he has referred to are nothing like the dimensions of 'our ordinary geometrical space' because, as he puts it,

[t]he three-dimensionality of the geometrical space is a characteristic of the 'world as a thing' whereas the fifteen dimensions of our model world refer to this world as a fact. [...] This 'logical space' is a fifteendimensional 'space' of possible places of states of affairs, whereas the ordinary geometrical space is a space of possible places of things. What the places in logical space are places of belongs to the category of facts, whereas what the places in ordinary geometrical space are places of belongs to the category of things. (ibid., p.43).

But it is precisely this fact, the fact that the world of the Tractatus is a "world as a fact' (Stenius ch.II and pp.43, 48, 52) which renders its 'logical space' incapable of being a phase-space. A phase-space could contain the world only if the world was understood as a thing but this, of course, is just what Tractatus 1.1 denies. So the 'logical space' that Stenius has in mind can't be a phasespace.

Max Black's A Companion to Wittgenstein's Tractatus contains more than one discussion of logical space, and it's not clear how they are supposed to be linked with one another. But the crucial thing about the two 'ways of using 
the analogy of logical space' which he regards as 'alternatives' (Black 1964, p.157) is that their denizens are propositions. So, in the first such way of using the analogy, Black tells us that 'logical space is the ordered system of all atomic situations', and atomic propositions correspond to points in logical space, while complex propositions correspond to volumes therein (ibid., pp.155, 157). And again, in the second way of using the analogy that Black envisages, what have 'co-ordinates' in logical space are propositions, and the co-ordinates of each proposition are the names of which it is composed (ibid., p.157). Whether or not either of these is the right way to understand what Wittgenstein meant by 'logical space', neither of them will make logical space into a phase-space, properly so-called. The operations that propositions admit of, such as negation, conjunction, and disjunction, simply cannot feature in phase-spaces. If logical space was to feature individual propositions as its denizens, for example, it's hard to see what negating one or more of those propositions would do to the phase-space, or what would correspond, in a phase-space, to propositions being conjoined or disjoined.

Finally, I come to the treatment in James Griffin's book Wittgenstein's Logical Atomism, also published in 1964. Griffin contends that the essence of what he calls 'Wittgenstein's metaphor about logical space' is in fact the mesh or grid which makes its appearance in Tractatus 6.341. He says:

The essence of the metaphor is, I think, comparison of a sentence with a point in a co-ordinate system, and so names with single co-ordinate numbers. In a given co-ordinate system putting two numbers together defines a point; in a given language putting two names together makes a statement. In this way, languages are a kind of logical co-ordinate system. And as there are different co-ordinate systems as a result of choosing different points of origin, different scales, and so forth, there are different representational forms in language. Now, from these roots all the rest of 
the metaphor grows. If two names are of forms permitting combination, their combination is logically all right; it would be as impossible for a conjunction of names to contradict logic as for a pair of co-ordinates to contradict geometry. A conjunction will always determine a 'logical place'... Furthermore, as in geometry to specify one set of co-ordinates involve the whole apparatus of grid, point of origin, and so on, so the determination of one logical place brings along with it a whole symbolism with all its rules and operations - or, as Wittgenstein puts it, the logical scaffolding will already be given by it. There is a logical place corresponding to every state of affairs. And facts, i.e. existent states of affairs, when put together, constitute the world, just as all points in a place which are occupied, when put together, constitute a geometrical figure, the sort which in 6.341 stands for the world which is to be described. (Griffin 1964, pp.103-4).

Whatever the merits of this comparison (see Pinkerton \& Waldie 1974, pp.9-13 for a stringent critique), it should be clear that nothing within it is a phasespace, since it doesn't feature objects whose properties change over time. In this model, in fact, as in Black's, objects (Tractarian objects, that is) figure only as the things that 'names' stand for, and if this is a model of logical space, names and the statements they make do dwell within logical space, but objects do not. This may fit with Wittgenstein's idea that facts (1.13), and situations (2.11, 2.202) are in logical space, but it does not allow that the denizens of logical space are the kinds of things (objects, processes, phenomena) which populate phase-spaces.

These commentators may have got Wittgenstein wrong in various ways, of course. But I don't think they have got him wrong in conceiving of a logical space as a quasi-linguistic space. It is this, though, which makes logical space such an unlikely candidate for being a phase-space. Phase-spaces can contain 
objects, processes, and their changing properties, but not propositions. If logical space does contain quasi-linguistic entities, such as the facts or situations which Wittgenstein explicitly tells us it contains (Tractatus 1.13, 2.11), or such as the propositions, facts or states of affairs which the commentators I have discussed have in mind, the 'force' of no such entity could, as Wittgenstein's explanation of logical space requires, 'reach through the whole of logical space' (Tractatus 3.42). Neither could a single proposition 'give' the whole of logical space, as an earlier clause in that same Tractarian proposition requires. Finally, although one may on such a conception be able to make sense of the idea that a tautology 'leaves open to reality the whole - the infinite whole - of logical space', it's hard to see how a contradiction could 'fill the whole of logical space, leaving no point of it for reality' (Tractatus 4.463). Indeed it's hard to see how a contradiction, that is, a proposition together with its negation, could feature 'in' logical space at all.

\section{Conclusion}

On none of these classic accounts of logical space, then, is logical space a kind of phase-space. Of course, there's still the possibility that none of the accounts I have covered is correct. (Pinkerton \& Waldie 1974 argue for this conclusion with respect to all but one of the accounts surveyed here). But if what I have said is correct, on no correct account of the Tractatus could its logical space be a kind of phase-space. Taken together with what I have suggested in the first half of this paper, I conclude that, whatever Boltzmann's influence on Wittgenstein might have been (for this, see Preston Forthcoming), claims that the logical space of Wittgenstein's Tractatus are modelled on Boltzmann's conception of phase-space are unjustified.

John Preston,

Department of Philosophy, 
The University of Reading, UK

j.m.preston@ reading.ac.uk

\section{Literature}

Anscombe, G. E. M. 1959. An Introduction to Wittgenstein's Tractatus. London: Hutchinson.

Black, M. 1964. A Companion to Wittgenstein's Tractatus. Ithaca: Cornell University Press.

Boltzmann, L. 1964. Lectures on Gas Theory. S. G. Brush (Trans.). Berkeley \& Los Angeles: University of California Press.

Boltzmann, L. 1974. Theoretical Physics and Philosophical Problems: Selected Writings, B. F. McGuinness (Ed.). Dordrecht: D.Reidel.

Griffin, J. 1964. Wittgenstein's Logical Atomism. Oxford: Clarendon Press.

Hacker, P. M. S. 1972. Insight and Illusion: Wittgenstein on Philosophy and the Metaphysics of Experience. Oxford: Oxford University Press.

Hyder, D. 2002. The Mechanics of Meaning. Propositional Content and the Logical Space of Wittgenstein's Tractatus. Berlin \& New York: Walter de Gruyter.

Janik, A. S. 2006. Assembling Reminders: Studies in the Genesis of Wittgenstein's Concept of Philosophy. Sweden: Santérus Academic Press.

Janik, A. S., \& Toulmin, S. E. 1973. Wittgenstein's Vienna. New York: Simon $\&$ Schuster.

Lockwood, M. 2005. The Labyrinth of Time: Introducing the Universe, Oxford: Oxford University Press.

Lützen, J. 1990. Joseph Liouville 1809-1882: Master of Pure and Applied Mathematics. New York: Springer Verlag.

Nolte, D. D. 2010. "The Tangled Tale of Phase Space", Physics Today April 2010, 33-38.

Pinkerton, R. J. \& Waldie, R. W. 1974. "Logical Space in the Tractatus", 
Indian Philosophical Quarterly 2, 9-29.

Preston, J. M. Forthcoming. "Wittgenstein, Hertz and Boltzmann", in: H-J. Glock \& J. Hyman (eds.), The Blackwell Companion to Wittgenstein, Oxford: Wiley-Blackwell.

Stenius, E. 1960. Wittgenstein's Tractatus: A Critical Exposition of the Main Lines of Thought. Oxford: Blackwell, and Ithaca: Cornell University Press.

Toulmin, S. E. 1969a. “Ludwig Wittgenstein”, Encounter, January 1969, 58-71. Toulmin, S.E. 1969b. "From Logical Analysis to Conceptual History", in: P. Achinstein \& S. E. Barker (eds.), The Legacy of Logical Positivism: Studies in the Philosophy of Science, Baltimore: The Johns Hopkins Press, 25-53. 